\title{
Waste heat recovery technology of iron and steel enterprises
}

\author{
Shanshan $\mathrm{Xie}^{1, \mathrm{a}}$ Hui Li ${ }^{1, \mathrm{~b}}$ \\ ${ }^{1}$ College of Metallurgy and Energy, North China University Of Science And \\ Technology, Tangshan Hebei 063009, China \\ a729055633@qq.com ,'Ih@ncst.edu.cn
}

Key words: Iron and steel enterprise; energy saving; waste heat recovery; recycling

Abstract: In recent years, the Chinese iron and steel enterprise energy resources conservation technology progress and key generic technology development and application, including CDQ technology, coal moisture control technology, sintering waste heat recovery and utilization, blast furnace top gas residual pressure power generation technology, converter negative energy steelmaking technology, steel billet hot charging and hot feeding technology and so on, and describes the sources of energy saving technology research development trend.

\section{Introduction}

Iron and steel enterprises in the consumption of energy to promote the transformation of the material will produce a lot of waste heat, the effective recovery of various waste heat can be used to further energy saving in the iron and steel enterprises in the direction and ways. Vigorously develop and application of science and technology to save resources and environmental protection, strengthen scientific research and technology development, scientific and rational use of energy, water and other valuable resources, improve the protection of resources and energy for the development of China's iron and steel enterprises to ease the severity of environmental problems caused by excessive consumption of resources, the sustainable development of China's iron and steel enterprises in the process, technology and equipment, and lay a solid foundation.

\section{Energy distribution and recovery potential of waste heat in iron and steel enterprises}

Waste heat energy refers to the main production process of the main production process of the heat carrier to the environment temperature as the basis for the release of heat and discharge of energy in addition to other kinds of energy (such as pressure, chemical energy, etc.).

Waste heat recovery of iron and steel enterprises in our country ${ }^{[1]}$ is $207.3 \mathrm{~kg}$ (standard coal) / (T steel), the recycling rate is $45.6 \%$. Among them, the total waste heat resources is $243.8 \mathrm{~kg}$ (subscript) / ( T steel), recycling $36.8 \mathrm{~kg}$ (standard coal) / ( $\mathrm{T}$ steel), recycling rate is only 211.3 ; more than $15.1 \% \mathrm{~kg}$ (standard coal) / ( $\mathrm{T}$ steel), recycling $170.5 \mathrm{~kg}$ (standard coal) / ( $\mathrm{T}$ steel), recycling utilization rate of $80.7 \%$.

\section{Coking process}

In the process of coking production, the temperature range of two energy to the red coke 950-1050, and the flue gas is 200, the sensible heat and pressure energy belong to the waste heat. Carbon is the basic element of the coking process, which has great potential for energy saving and reducing consumption. From the loss distribution of heat in the coke production process, the heat of $950-1050$ is $37 \%$, the heat of the coke oven is, the heat of the $650-850$ is $36 \%$, and the heat of the furnace is $17 \%$. The surface heat loss is $10 \%$. Visible coking process can be used to recover the waste heat resource is considerable. 


\section{Sintering / pellet process}

In iron and steel production process, the energy consumption of the sintering process is about $10 \%$ of the total energy consumption, after the iron making process, in the second. Sintering process of waste heat resources including sintering production process emissions significantly heat and sinter products sensible heat of two parts, the former is pulled out from the lower sintering machine bellows, carried by the sintering waste gas thermal physics, which is discharged from the bellows at the top of the sinter cooling machine carried by air or cooling exhaust gas thermal physics, the two accounted for about $20 \%$ and $40 \%$ of the total quantity of heat of sintering process. The study shows that the sintering process of the cooling machine and the sintering flue gas is about $50 \%$ of the total heat.

At present, the use of domestic sintering waste heat recovery are mainly in three ways: one is directly to the waste gas after purification as ignition furnace combustion air or used for preheating mixed material, to reduce the fuel consumption, this method is relatively simple, but the residual heat utilization Co., generally not more than $10 \%$ of the volume of flue gas; the second is waste flue gas device or a waste heat boiler to generate steam through the heat pipe, incorporated into the whole plant steam pipe network, replace part of the coal-fired boiler, waste heat boiler to generate steam to drive steam turbine to generate electricity.

\section{Iron making process}

There are many types of waste heat energy in the process of iron making, and the amount of waste heat is relatively large. The waste heat is mainly in blast furnace slag sensible heat, hot blast furnace cooling water, blast furnace gas sensible heat and hot air stove flue gas sensible heat. The first 3 waste heat recovery, the last 1 hot blast furnace flue gas is the main heat exchanger and the recycling rate is $30.1 \%$. The main energy resources in the process of the iron making process include blast furnace gas and blast furnace gas chemical energy ${ }^{[2]}$. The former is mainly through the top pressure difference generation recycling pressure, the recovery utilization rate of $25.2 \%$, popularity of technology efficiency is low, which is leading to the main reason for the low recovery rate; the latter divergence rate is very high. Therefore, it is still the included in the residual heat and energy statistics, the blast furnace gas recovery using rate was $88 \%$.

The slag is injected into the container, and the cooling water is circulated around the container, and the slag is recycled in the form of steam. The thermal recovery of the two methods is low, the blast furnace slag is very hot.

\section{Steelmaking process}

At present, there are two ways in the domestic and foreign converter gas (gas) dust removal, namely, OG wet dust removal system and LT dry dust removal system. The two methods have different dust removal methods, but their essence is wet, that is, the converter gas is cooled by the cooling of the converter, and the gas is sprayed or sprayed with $800-1000$, which makes the flue gas cooling down to 70 or 200 . In the converter gas, a large amount of sensible heat can not be used, which is a waste of energy, increase the water or steam consumption, but also produce a large number of process wastewater.

The negative energy of the converter is the total energy consumed in the process of converter steelmaking is less than that of the total energy. The energy consumption in the process of converter steelmaking mainly includes: oxygen, nitrogen, coke oven gas, electricity, steam and new water. The main factors that affect the energy consumption of the converter are the recovery of converter gas, the recovery of steam, oxygen and power consumption. Converter gas recovery and steam recovery is the key to realize the negative energy of the converter. 


\section{Energy distribution and recovery potential of waste heat in iron and steel enterprises}

\section{dry quenching technology}

Coke dry quenching (CDQ) is the abbreviation of coke dry quenching (CDQ (coke dry quenching) is relative to wet coke quenching with inert gas out of the red hot coke a coke quenching method. Recovery of sensible heat utilization of CDQ coke red, improving coke quality, coke quenching operation reduce pollution to the environment ${ }^{[3]}$.

CDQ is the use of cold inert gas (150 DEG C) in the dry quenching chamber and the red hot coke (sintered DEG C) heat and cooling coke (200 DEG C), the absorption of coke heat an inert gas (850 DEG C) heat transfer to the CDQ boiler to generate steam. The inert gas is cooled by the circulating air blower to the dry quenching tank. MV CDQ boiler produced steam into the factory (or high) or steam pipe network for power generation.

\section{humidity control technology}

Coal (CMC) is the abbreviation of Moisture Control (Process), which is a kind of coking coal pretreatment process, which is used to remove a portion of the water and keep the water stable in the furnace.

The basic principle of humidity and humidity is to use external heating energy to dry and dehydration coking coal in coking furnace, and to adjust the moisture of coal, to control the energy consumption, improve the coke oven operation, improve the coke quality or expand the coking technology of coal blending ${ }^{[4]}$. After the coal is dry or wet, the water of the boiler is reduced and stable.

\section{Sintering waste heat power generation}

According to the thermodynamic first and second law, recycling the sintering production process generated waste heat resources must follow the fractional recovery and temperature counterparts, cascade utilization principle, in recycling and the use of waste heat resources of different qualities to try to make the quantity and quality of the match, and strive in the waste heat recovery and utilization between the energy difference of the minimum. According to the characteristics of low grade of waste heat, the two kinds of waste heat resource of cooling gas and sintering gas are classified and recycled, and the heat of the various grades of the grade of the process are used to improve the sintering process.

For words is of high temperature heat source first of all, the implementation of dynamic recovery and for waste heat boiler to produce high quality steam and power generation; for low temperature heat for direct heat recovery and for preheating and drying and sintering raw material and as ignition furnace combustion air and hot air sintering production etc.

\section{Main waste heat energy utilization technology of iron and steel enterprises}

Efficient recycling of waste heat energy resources is the future of the iron and steel industry, the potential of energy saving and the main direction. Iron and steel joint enterprise waste heat recovery and utilization of waste energy, although there is a big improvement, but compared with the international advanced level is still a big gap.

We want to learn and digest foreign advanced technology on the basis of the introduction and absorption of integrated innovation, for the new generation of iron and steel process to provide technology and equipment support for the recovery of waste heat recovery. In order to change the single indirect recovery of waste heat resource, the indirect and direct combined recovery, the recovery of the high, medium and low temperature of three kinds of temperature is changed in the past. 


\section{Acknowledgements}

This work was financially supported by the National Natural Science Foundation of China (Grant No. 51401075)

\section{Reference}

[1]Zhongwu Lu,Jiuju Cai. The influence of logistics on energy consumption in steel production process [J]. Journal of metals. Vol. 4 (2000), 36,p. 371-378. In Chinese

[2]Zhongwu Lu,Anguo Xie, Dagang Zhou. On the China direction and the way of energy saving in iron and steel industry [J]. Iron and steel.Vol. 2 (1996), 3L,p. 54-58. In Chinese

[3]Jiuju Cai,Jianjun Wang, Chunxia Chen, et al. Recovery and utilization of waste heat resources in iron and steel enterprises [J]. Iron and steel,Vol. 6 (2007), 42,p. 1-7. In Chinese

[4] Jiuju Cai,Tao Du,Zhongwu Lu. Research method of environmental load evaluation system for iron and steel production process [J]. Iron and steel, Vol.8 (2002), 37 ,p.66-70. In Chinese 